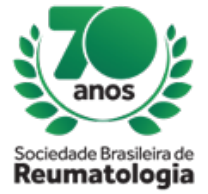

\title{
COMPARISON OF LUPUS PATIENTS WITH EARLY AND LATE ONSET NEPHRITIS: A STUDY IN 71 PATIENTS FROM A SINGLE REFERRAL CENTER
}

Juliana Delfino (Rheumatology Unit - Hospital Universitário Evangélico Mackenzie, Curitiba, PR, Brasil), André Adalberto Petry (Rheumatology Unit - Hospital Universitário Evangélico Mackenzie, Curitiba, PR, Brasil), Jady Elen de Pontes (Rheumatology Unit - Hospital Universitário Evangélico Mackenzie, Curitiba,

PR, Brasil), Anauá Fernanda dos Santos Cavalcante (Rheumatology Unit - Hospital Universitário Evangélico Mackenzie, Curitiba, PR, Brasil), Carla Luchese de Almeida (Rheumatology Unit - Hospital Universitário Evangélico Mackenzie, Curitiba, PR, Brasil), Deborah Colombo (Rheumatology Unit Hospital Universitário Evangélico Mackenzie, Curitiba, PR, Brasil), Thiago Alberto Fernandes Gomes dos Santos (Rheumatology Unit - Hospital Universitário Evangélico Mackenzie, Curitiba, PR, Brasil), Thelma Laroca Skare (Rheumatology Unit - Hospital Universitário Evangélico Mackenzie, Curitiba, PR, Brasil)

\section{BACKGROUND}

Systemic lupus erythematosus (SLE) is a chronic autoimmune inflammatory disease of connective tissue, with wide phenotypic, severity and clinical course variability. Morbidity and mortality are particularly high in patients with renal impairment. There are few data in the literature addressing the characteristics of early and late onset lupus nephritis (before and after 36 months of SLE diagnosis).

\section{MATERIALS AND METHODS}

From 238 medical records of patients with lupus nephritis (NL), a total of 71 followed for at least 2 years after end of treatment was obtained. Epidemiological (race, sex, age at onset of SLE, age of onset of nephritis, smoking history) and clinical data including type of glomerulonephritis, degree of chronicity and activity by biopsy, response to treatment, time to the first glomerulonephritis relapse, and laboratory characteristics. Regarding the treatment, the patients were classified as responders, non-responders and partially responders to treatment after 12 and 24 months of treatment. Patients were divided into early lupus nephritis patients - up to 36 months after diagnosis of SLE and patients with late lupus nephritis 36 months after SLE diagnosis.

\section{RESULTS}

About $50(71.4 \%)$ patients were identified as having early onset lupus nephritis and $21(29.5 \%)$ as having late lupus nephritis. The mean age at diagnosis of lupus nephritis was at age 30 years. It was found that younger patients (median age 27 years) had earlier nephritis compared to older patients, with $p=0.01$. No statistically significant differences were found between activity scores, chronicity, and severity of renal function impairment and progression to dialysis in patients with early and late NL (all with $p=n s)$. Also, no differences were noted in $\mathrm{C} 4$ and $\mathrm{C} 3$ complement levels, positivity for anti-DNA, proteinuria, creatinine levels between the 2 groups, one and after 2 years of treatment. The level of hemoglobin in patients with early-onset NL at the time of diagnosis of nephritis was lower when compared to patients with late NL, and this finding was statistically significant $(p=0.02)$.

\section{CONCLUSION}


Data from the present sample suggest that early and late onset lupus nephritis is similar from clinical, serological and laboratory point of view and that severity and prognosis do not differ significantly between these two groups. 